\title{
Technology, Customization, and Reliability
}

\author{
Michael D. Johnson \\ University of Michigan Business School, 701 Tappan Street, Ann Arbor, MI 48109-1234, USA \\ John E. Ettlie \\ College of Business, Rochester Institute of Technology, 107 Lomb Memorial Drive, Rochester, \\ NY 14623-5608, USA
}

\begin{abstract}
This research examines the relative importance that customers place on product reliability, or things-gonewrong, and customization, or things-gone-right, across a range of industrial settings. We integrate an evolutionary theory of technology with a dynamic theory of competition to predict that: (1) when technological intensity is relatively low or high, customers place greater value on customization and (2) when technological intensity is more intermediate, product reliability and customization are more equally important. The predictions are tested and supported using data from the American Customer Satisfaction Index (ACSI) survey.
\end{abstract}




\section{Introduction}

Quality experts and customer satisfaction researchers emphasize two general types of quality, the degree to which a good or service provides key customer requirements, or customization, and how reliably these requirements are delivered, or reliability (Fornell, Johnson, Anderson, Cha, \& Bryant, 1996; Juran \& Gryna, 1988). Firms face very different strategic implications for improving quality depending on which of these dimensions is most important to customers (Johannsen, 1996a, 1996b; Raynor, 1992). Improving customization requires more of a joint customer-technology focus (Griffin \& Hauser, 1996), while improving reliability requires more of an internal process improvement or quality control focus (Deming, 1981; Feigenbaum, 1991).

There is disagreement, however, as to the relative importance of customization and reliability across contexts. One argument is that companies have generally mastered the secrets of internal quality or improved reliability. Now that the "low hanging fruit" has been fixed, investing in R\&D, combined with a deep understanding of customers' needs, is the key to reaching the "'high hanging fruit." Thus, customization should be the key driver of satisfaction and loyalty for products and services alike (Fornell et al., 1996). Alternatively, the relative importance of customization and reliability may depend on the stage of the product and technology life cycle (Ettlie, 2000). Whereas customization should be more important early in the lifecycle, reliability becomes more important as the product category matures. Another argument in favor of reliability is that many internal quality programs were never implemented correctly in the first place (Cole, 1998). Although there were initial successes in the TQM movement, rarely were the changes institutionalized. Thus, reliability may remain critically important to a firm's success.

The goal of this research is to provide insight into this debate. We develop a theoretical model that predicts the relative importance of reliability versus customization in driving customer satisfaction and loyalty. The model integrates a dynamic theory of competition and market behavior from marketing theory (Dickson, 1992; Hunt \& Morgan, 1995) with technological intensity trade-offs from the management of technology literature (Nelson \& Winter, 1982; Utterback \& Abernathy, 1975).

Our model predicts that when technological intensity is either relatively low or high, customers place greater relative value on customization. When technological intensity is more intermediate, product reliability and customization are more equal in importance. The predictions are tested using data from the American Customer Satisfaction Index (ACSI) survey. We find strong support for this hypothesized inverted U-shaped relationship between technological intensity and the relative importance of reliability versus customization in driving satisfaction and loyalty.

\section{Customization, reliability, and technological intensity}

The definition of quality has evolved over time. A common view toward the latter part of the 20th century is the definition that quality is conformance to requirements and customer specifications (Reeves \& Bednar, 1994). This definition emphasizes two underlying dimensions of quality. One is having a proper set of customer-defined requirements or specifications in the first place. The second is having a production, delivery, and maintenance process that conforms to the specifications. These dimensions are central to Juran's concept of “fitness for use'” (Juran \& Gryna, 1988). Customer-defined quality results from product performance, defined as the degree of customization, and freedom from deficiencies, or how reliably the product meets its specifications. We refer to these two components of quality as customization and reliability.

An advantage of this two-dimensional view of quality is that it allows us to make comparisons across very different firms and industries. Within any given industry, firm, or even market segment, the quality dimensions that drive customer satisfaction and loyalty are many and varied (Garvin, 1984; 
Gustafsson \& Johnson, 1997; Parasuraman, Zeithaml, \& Berry, 1985). Yet, all the dimensions may be viewed, at some level, as falling under the categories of customization and reliability.

There is no general agreement as to the relative importance of these quality dimensions across contexts. Corporate strategy and marketing scholars have argued that companies have more or less mastered the secrets of internal quality, or improved reliability, decreasing their value as a source of competitive advantage. As we have moved from a focus on internal quality to a focus on customers and market pressures, squeezing more variance out of a manufacturing process should not increase quality and satisfaction as much as tailoring goods and services to meet customer needs (Fornell et al., 1996; Johnson, 1998). The tools for improving reliability are well known and easily disseminated, which makes it difficult for firms to use reliability to differentiate themselves in the eyes of customers. Rather, differential advantage is more likely to come from factors related to customization (Porter, 1996).

Research on strategic quality is consistent with this view. Johannsen’s (1996a, 1996b) strategic quality management (SQM) framework emphasizes that strategic management and total quality management should be an integrated management process. Similarly, Raynor (1992) views strategic quality as an entire system of thought that goes well beyond functional excellence. Inspired by Japanese hoshin kanri or policy deployment (Imai, 1997), SQM views quality management as an integral part of an overall or "total"' strategy, planning, and implementation process.

However, significant barriers remain between strategic planning and the implementation of quality practices (Morgan \& Piercy, 1998). Most organizations continue to use quality management on a strictly tactical basis. While they implement quality circles, process reengineering, cycle time reduction, or statistical process control, organizations fail to address questions related to strategic quality and the resulting customization of their product/service mix (Recardo, 1993). For example, in an earlier study of 35 firms' experience with quality function deployment (QFD), we found a basic tension between a firm's ability to improve internal operations and focus on customers (Ettlie \& Johnson, 1994). Specifically, benchmarking on best practices to improve one's own operations led to a decrease in customer focus. Taken together, the strategic quality literature is thus consistent with the marketing literature in suggesting that customization is the neglected dimension in need of broad-based improvement across firms and industries.

Fornell et al. (1996) provide empirical support for this proposition using the 1994 baseline ACSI data. Using customization and reliability as two different measures of overall quality, the measurement loadings (the correlations between the customization and reliability measures and the overall quality index) suggest that customization is more important across industries. The average loading for customization was .906 compared to .770 for reliability. For all industry sectors, the loadings for customization are higher than the loadings for reliability.

In contrast, the management of technology literature suggests that reliability should be more important, at least in certain contexts. The evolutionary theory of technology (Nelson \& Winter, 1982; Utterback \& Abernathy, 1975) suggests that there are stages of product maturity at which process improvement (reliability) is more important to customers than product innovation (customization). Whereas product innovation is more critical in the early phases of a product life cycle, process improvement becomes the more critical dimension as the product technology matures. This suggests that reliability should become more important after the dominant design has emerged and product competition has stabilized. This maturity is typical of many of the industries included in the ACSI survey.

Cole (1998) provides another argument as to why reliability continues to be an important source of differentiation. The way that internal quality improvement is typically deployed, as through Crosby's (1980) "quality is free”' initiative, may actually hurt the cause of a sustained process quality. Such programs are rarely company-wide, and often require employees to follow agreed upon requirements without a mechanism for continuous improvement. 
A more complete picture of the relative importance of customization and reliability requires an integration of perspectives. From marketing, we borrow from the dynamic theories of competition and market behavior that have evolved in recent decades. We integrate the dynamic view of competition with the evolutionary theory of product versus process innovation.

\subsection{Dynamic theory of competition}

Dynamic theories of competition and market behavior have existed for some time within the Austrian School (Garrison, 1978; Reekie \& Savitt, 1988). The dynamic view took hold in marketing through Alderson's work on sorting and transformation processes and his concept of market matching (Alderson, 1957, 1965). A primary feature of Alderson's work is its focus on the process of how markets operate. Alderson's framework replaces homogeneity with heterogeneity as the economic norm. This heterogeneity exists with respect to both that which customers demand and that which suppliers offer. Marketing is viewed as a dynamic or ongoing process of attempting to attain a match between heterogeneity in demand and heterogeneity in supply (versus the attainment of a static equilibrium).

More recent approaches build upon Alderson and the Austrian School. Dickson's (1992) framework distinguishes between macromarket behavior and firm behavior (competitive rationality). The macromarket is characterized by continuous changes in both the heterogeneity of supply and the heterogeneity of demand. That is, both economic processes and buyers preferences are constantly changing due to changes in space, time, technology, form, and information. Individual firms competing in this environment vary in three important ways. First is their ability and willingness to innovate or improve. Second is their ability and willingness to learn from their experiences and/or imitate what others are doing. Third is their ability and willingness to follow through and implement what they have innovated, learned, and imitated.

Dickson argues that the differences in firms' abilities and motivations to innovate, learn, and implement explain why total congruence between heterogeneity in demand and heterogeneity in supply is constantly sought but never achieved. Similarly, Hunt and Morgan (1995) argue that demand and supply are heterogeneous and constantly changing. These authors further emphasize that both customer information and firm information is imperfect and costly to obtain, which is consistent with the argument that congruence is constantly sought but not achieved. Overall, the dynamic approach predicts that there is a meaningful level of unmet customer needs in a market at any given point in time, regardless of product, market, or technology maturity.

\subsection{Evolutionary theory of innovation}

The dynamic theory in marketing has a parallel in the form of an evolutionary theory of technology and innovation (Utterback \& Abernathy, 1975). The evolutionary approach challenges an earlier model, advanced by March and Simon (1958), that there is a continuous steady-state pressure towards innovation due to the notion that aspiration levels do not remain constant but tend to rise slowly over time.

Utterback and Abernathy (1975) proposed an alternative model of the "evolution of the productive segment" of a firm. They predicted and found a systematic pattern of innovation that develops as a company matures that involves three stages. Early in a product life cycle, product innovation (dramatically improving a product's specifications) is stressed relative to process innovation (improving a product's production, delivery, and maintenance processes). Product innovation is a differentiator when only one or a subset of competing firms has the technology. In Stage 2, imitation and competition increases, product niches are filled, and industry shake out occurs. As a result, product innovation becomes less important in differentiating among competitors. The basis of competition forces players to shift to process innovation as reliability and cost reductions become greater customer concerns. For 
example, in comparing the automotive and electronic industries, Choi and Rungtusanatham (1999) find that SQM is more actively practiced in the automotive industry where the market is more mature and the life cycles longer. In Stage 3, competition is based primarily on cost. R\&D-based product innovation is quite low. Significant customization still occurs, but in a much different fashion from the early stages of a technology life cycle. Firms “backtrack” or “'demature”' by using existing technology in new and creative ways to better meet the needs of particular market segments. From a cost standpoint, firms also move production overseas when threatened in stage three by competitors.

Assumptions in Utterback and Abernathy's approach were, in part, inspired by the view that investments in R\&D are often an ad hoc response to market evolution rather than a policy or strategy decision. Nelson and Winter (1982) argue that a firm cannot possibly find an optimal, equilibrium-based $\mathrm{R} \& \mathrm{D}$ strategy unless the cost of invention and demand is completely taken into account and all alternatives are considered, which is unlikely. Thus, the evolutionary approach, like the dynamic theory of competition in marketing, is consistent with the assumptions of the Austrian School. The theory takes a successful new technology or innovation as a starting point that is historically followed by a wave of minor innovations (Nelson \& Winter, 1982). Tushman and Anderson (1986) empirically demonstrate this pattern of innovation for three industries, including commercial aircraft.

As product innovation evolves, it faces a trajectory of diminishing returns in the form of a frontier of achievable capabilities. Trajectories can be specific to a particular case and can be complementary, like engine power and the streamlining of aircraft. But, more generally, natural trajectories seem to share the tendency of progressive exploitation of latent economies of scale (productivity gains) and increasing the mechanization and reliability of operations (process improvement). Under evolutionary theory, industries with rapid technical progress generally have high $R \& D$ expenditures. When $R \& D$ expenditures are smaller and become more concentrated, technical progress is slower.

\subsection{An integration of dynamic competition and evolutionary theory}

When taken together, the dynamic and evolutionary views provide a more complete model of just how important customization and reliability should be at different levels of technological intensity. Central to the dynamic theory of competition is that customer needs are constantly changing. Central to the evolutionary theory of technology are systematic changes in technological intensity vis-a ${ }^{\text {`-vis process }}$ improvement. Firms characterized by high R\&D intensity have a relatively low process improvement focus. Firms characterized by moderate R\&D intensity have a more equal product and process focus as process improvements and cost reductions become a more important means to compete. Finally, firms with a low or mature $R \& D$ intensity focus primarily on process improvements and productivity gains, often through means that do not require very large investments in either product or process technology (like quality improvement programs and customer service).

Now, consider the joint effects of the two theories on the relative importance of customization and reliability for customers. Our predictions here are based on the notion that at any given level of R\&D intensity, there are relatively stable differences across firms with respect to customization, reliability, satisfaction, and loyalty (Barney, 1991; Conner, 1991). These differences allow us to observe the impact of customization versus reliability on satisfaction and loyalty across firms. For high R\&D intensity firms, the emergence of new technologies and innovations provides a means of dramatically improving customer specifications, or customization, vis- $a{ }^{`}$-vis the technology being replaced (such as a new generation printer or PC). Thus, improvements in customization should have the greater impact on customer satisfaction and subsequent loyalty. This is consistent with Dickson's (1992) argument that a firm's ability and willingness to innovate is the first step in adapting to heterogeneous customer needs.

In contrast, firms that are more intermediate in their R\&D intensity find it more difficult to "push the envelope' of existing dominant designs (in terms of customer specifications) in a way that creates a 
competitive advantage. Both the marketing and technology management theories predict more imitation among such firms, gradually making differences in customization less of a differentiator. Following evolutionary theory, organizations shift their efforts to compete on process improvements and productivity gains. We thus predict that customization and reliability become more equal in importance for the customers of these firms.

For low R\&D intensity firms nontechnology-based process improvements and productivity gains (cost reductions) come to dominate firms' activities as they shift their resources even further from product to process as with continuous improvement programs. However, process innovations are subject to diminishing returns, both with respect to perceived reliability (as reliability becomes a "basic or expected' dimension; Kano, Seraku, Takahashi, \& Tsuji, 1984) and cost reductions (Best, 2000). Firms produce relatively mature products (soap, soft drinks, and gasoline) with very high reliability. As a result, reliability becomes less important to customers relative to moderate $R \& D$ intensity firms. At the same time, the dynamic theory of competition argues that the heterogeneity of customer demand has not remained static. Rather, it has continued to change and evolve through the course of an extended technology life cycle. Heterogeneity in demand, a lack of congruence between supply and demand, and a need for customization remain. (Ultimately, new technologies come along to help meet this need for customization.) Therefore, customization should once again become the more important driver of customer satisfaction and loyalty, and will likely be the focus of any, albeit diminished, technology resources available.

The type of customer who buys low, moderate and high R\&D products is also likely to vary. The more innovative the technology, the more early adopters are purchasing and using the product (Ettlie, 2000). These early adopters are generally better problem solvers (Howard, 1983). If reliability problems do occur with the technology, early adopters are more willing and able to deal with the problems themselves. Consistent with our arguments, "things gone wrong'" should not be particularly important to these customers. Rather, they place great value on improving "things gone right." The more mature the technology, the broader and more risk averse the customer base making reliability a more important issue, at least when it is a basis for differentiation. Our arguments suggest that this reliability differentiation exists for firms that are more intermediate in their technology life cycle and R\&D expenditures. The rationale for this argument is that firms at the beginning and during the second stage of the technology evolution have the greatest resources available for technology investments, whether these investments focus on product improvements or new processing technologies.

To illustrate our predictions, consider an example involving three products offered by different firms in our subsequent empirical study: beer, refrigerators, and PCs. A relatively high level of R\&D expenditure characterizes certain PC firms. New PC designs and technologies result in dramatic increases in the ability of the product to meet customer needs. Customers are willing to put up with some level of "things gone wrong' because the increase in "things gone right"' is so great. Refrigerator production involves a more moderate level of R\&D expenditure and market maturity. While there are still significant increases in customization due to technology that impact satisfaction and loyalty (such as new interior designs and features), reliability and cost become more salient and important. Finally, beer production is a relatively mature technology (firms producing beer have relatively low $R \& D$ expenditures). The maturity of the technology means that process improvements have already been exploited to a large degree; there are relatively few "things gone wrong'” across competitors. But, customer needs continue to change and shift in a dynamic fashion. Significant demand heterogeneity remains. In response, producers become creative with existing technologies (Utterback and Abernathy's “dematuration” process) to provide an ever changing and wider variety of beers that vary on both functional and social psychological dimensions in an attempt to adapt to changing customer needs. The emergence of microbreweries is as an 
example of dematuration of the malted beverage industry. Customization again becomes the key to increasing satisfaction and loyalty, but existing technology is used for this transition.

\subsection{Hypotheses}

We formalize our predictions as hypotheses, one for each of three levels of technological intensity:

Hypothesis 1: For high-technology intensive firms, perceived product customization has a greater impact on satisfaction and subsequent loyalty than does perceived reliability.

Hypothesis 2: For moderate-technology intensive firms, perceived product customization and perceived reliability have equal impacts on satisfaction and subsequent loyalty.

Hypothesis 3: For low-technology intensive firms, perceived product customization has a greater impact on satisfaction and subsequent loyalty than does perceived reliability.

\section{Methodology}

The hypotheses are tested using a sample of firms that vary in their base level of technological intensity as measured by investments in research and development (R\&D) over a finite period of time. The firms are all part of the ACSI database (Fornell et al., 1996). We categorize the firms into low, moderate, and high R\&D intensity respectively and then explore the relative impact of customization versus reliability on satisfaction and loyalty for each category of firms.

It should be noted that our data is a level of aggregation above our theoretical predictions.

That is, our R\&D spending and customer data is at the firm level, while our theoretical arguments pertain to particular product categories and technology life cycles. This is because both our R\&D and customer data is available at the firm level. Thus, each of our observations represents some average over a firm's offerings. Importantly, the theory still applies to these averages. Contrast this with the case where the theory applies to an entire firm while the data is from particular and potentially idiosyncratic product categories. In the next sections, we describe the sample of firms, their R\&D classifications, and the customer survey information used in our analyses.

\subsection{The sample}

We focus on the 53 manufacturing firms in the ACSI survey that also publicly report R\&D spending, which serves are our proxy for technological maturity. We use satisfaction survey results from 1994 through 1998. In a very small number of cases (49 out 1060 observations or 4.6\%) there were missing values for a particular firm-level survey observation (for customization, reliability, satisfaction, or loyalty). In these cases, we replaced the value with the previous year's value for the firm on the variable. This is consistent with the observed stability of the ACSI measures over time.

The R\&D measures are taken from 1993 through 1997, and they consist of research intensity (R\&D spending as a percentage of sales). Although a variety of measures of evolution of the productive segment technology is possible, the most commonly used is R\&D intensity for a number of reasons. First, most firms keep track of R\&D expenditures and sales, so the number is easy to calculate. Second, this ratio is usually quite stable over time for firms and is extremely useful for policy analysis (see, for example, Lin, 1996; Margolis \& Kammen, 1999; Viscusi \& Moore, 1993). The 1-year lag in R\&D versus the survey data is based on the assumption that it will take at least 1 year for investments in technology to show up in products that customers have had the time and experience to be able to evaluate. 
A principal-components analysis of the 4 years of R\&D data across firms reveals that a single factor explains $96.8 \%$ of the variation in R\&D spending. The loadings for the factor ranged from 0.981 to 0.987. Consistent with the studies cited above, this supports an extremely stable level of R\&D spending by firms over the limited time period studied. These results suggest that the technology life cycles being studied involve much longer time periods. Consistent with our analyses, the R\&D differences that do exist are more firm and industry based. A k-means clustering analysis reveals three distinct clusters of firms that differ significantly in their $R \& D$ spending $(F=269.056, P<.001)$. A histogram of these $R \& D$ intensity levels for the firms similarly reveals that the firms fall naturally into low, moderate and high intensity categories.

Table 1 shows the resulting classification of firms. The low intensity firms $(n=28)$ had an average R\&D spending from 1993 through 1997 of 1.00\% of sales (observations ranging from $0.28 \%$ to 2.18\%). The moderate intensity firms $(\mathrm{n}=11)$ had an average $\mathrm{R} \& \mathrm{D}$ spending of $3.42 \%$ of sales (ranging from $2.72 \%$ to $4.39 \%$ ), while the high intensity firms $(n=14)$ spent $5.48 \%$ of sales on R\&D (ranging from $4.98 \%$ to $7.42 \%$ ). The firms are predominately manufacturing firms (where the core product is a physical good), although some telecommunications companies are included (three in the low R\&D intensity category and one in the moderate R\&D intensity category). It is interesting that, in more than one case, firms from the same industry (such as food products, electronics, automotive, and telecommunications) span more than one R\&D category. Among packaged goods companies, for example, Kellogg is categorized as low while Proctor and Gamble is moderate. Among personal computer companies, Compaq is moderate while Apple is high. And, among consumer electronics companies, Zenith is moderate and Sony is high. This demonstrates that the categories are not simply a function of industry differences.

\subsubsection{The ACSI data}

We use customer-based measures of perceived customization, reliability, overall satisfaction, and loyalty from the ACSI survey. (For a complete description of the ACSI survey and methodology, see Fornell et al., 1996.) The ACSI model uses quality as a driver of customer satisfaction while satisfaction drives customer loyalty. The model is estimated for each of approximate 200 firms annually and based on a random sample telephone survey of approximately 250 of a firm's customers. Our interest is in the overall satisfaction index, loyalty index, and the survey ratings for the two dimensions of quality (customization and reliability) for each firm in a given year. Specifically, we examine the impact that customization and reliability ratings have on the satisfaction and loyalty indices to determine the relative importance of each quality dimension and how it varies by the level of technological intensity of a firm.

The satisfaction index is a weighted average of three overall evaluation measures: (1) an overall rating of satisfaction, (2) the degree to which performance falls short of or exceeds expectations, and (3) a rating of overall performance relative to the customer's ideal good or service in the category. The 1-10 point scale ratings for these measures are combined into a weighted average and rescaled to provide a 0 100-point satisfaction index (see Fornell et al., 1996 for details). Our measures for customization and reliability are on their original $1-10$ point scales (where 1 = poor customization/reliability and $10=$ excellent customization/reliability). 
Table 1

Categorization of firms by R\&D category

\begin{tabular}{lll}
\hline Low R\&D firms & Moderate R\&D firms & High R\&D firms \\
\hline Amoco & AT\&T & Apple \\
Atlantic Richfield & Chrysler (Chrysler) & GM (BOC) \\
Borden & Chrysler (Dodge-Plymouth) & GM (Chevrolet-GEO) \\
Campbell Soup & Chrysler (Jeep/Eagle) & GM (Pontiac) \\
Chevron & Compaq & GM (Saturn) \\
Clorox & Emerson Electric & Honda \\
Colgate Palmolive & Ford (Ford) & Hewlett Packard \\
Adolph Coors & Ford (Lincoln-Mercury) & IBM \\
Exxon & Proctor \& Gamble & JVC \\
General Electric (Appliances) & Volvo & Mercedes Benz \\
General Mills & Zenith Electronics & Mitsubishi Electronics \\
GTEl & & Philips Electronics \\
Hershey & & Sanyo US \\
Kellogg & & Sony \\
Maytag & & \\
Mobil & & \\
Nestle & & \\
Nike & & \\
Nynex & & \\
Pacific Telesis Group & & \\
Phillip Morris & & \\
Phillips Petroleum & & \\
Quaker Oats & & \\
Ralston Purina & & \\
RJR Nabisco & & \\
Shell & & \\
Texaco & & \\
Whirlpool & & \\
\hline & & \\
\hline & & \\
\hline
\end{tabular}

Customization is an evaluation of how well the product has fit the customer's personal requirements. Reliability is an evaluation of how often things have gone wrong with the product.

Loyalty in the model is a customer's psychological predisposition to repurchase from a particular product or service provider. There are two measures of customer loyalty in the ACSI model. The first is a rating of repurchase likelihood. The second is constructed from two survey ratings: the degree to which a firm could raise its price(s) as a percentage before the customer would definitely not choose to buy from that firm again the next time (given the customer has indicated that he or she is likely to repurchase), and the degree to which a firm would have to lower its price(s) as a percentage before the customer would definitely choose again from that firm the next time (given the customer has indicated that he or she is unlikely to repurchase).

It is important that any differences that we observe with respect to our R\&D categories are not due to simple differences in the levels of perceived customization and reliability per se. As a pretest, a simple MANOVA analysis was performed using R\&D category as the independent variable and customization and reliability as dependent variables. The results show that while the two dependent variables are correlated, their levels do not differ significantly across R\&D categories.

\subsubsection{Empirical model and analyses}


Our primary analyses use a quality-satisfaction-loyalty model to estimate the pattern of effects for each of the low, moderate, and high R\&D intensity categories. In the model, presented in Fig. 1, our two general dimensions of quality (customization quality and reliability quality) impact overall satisfaction, which in turn impacts loyalty. The model estimations serve two important purposes. First,

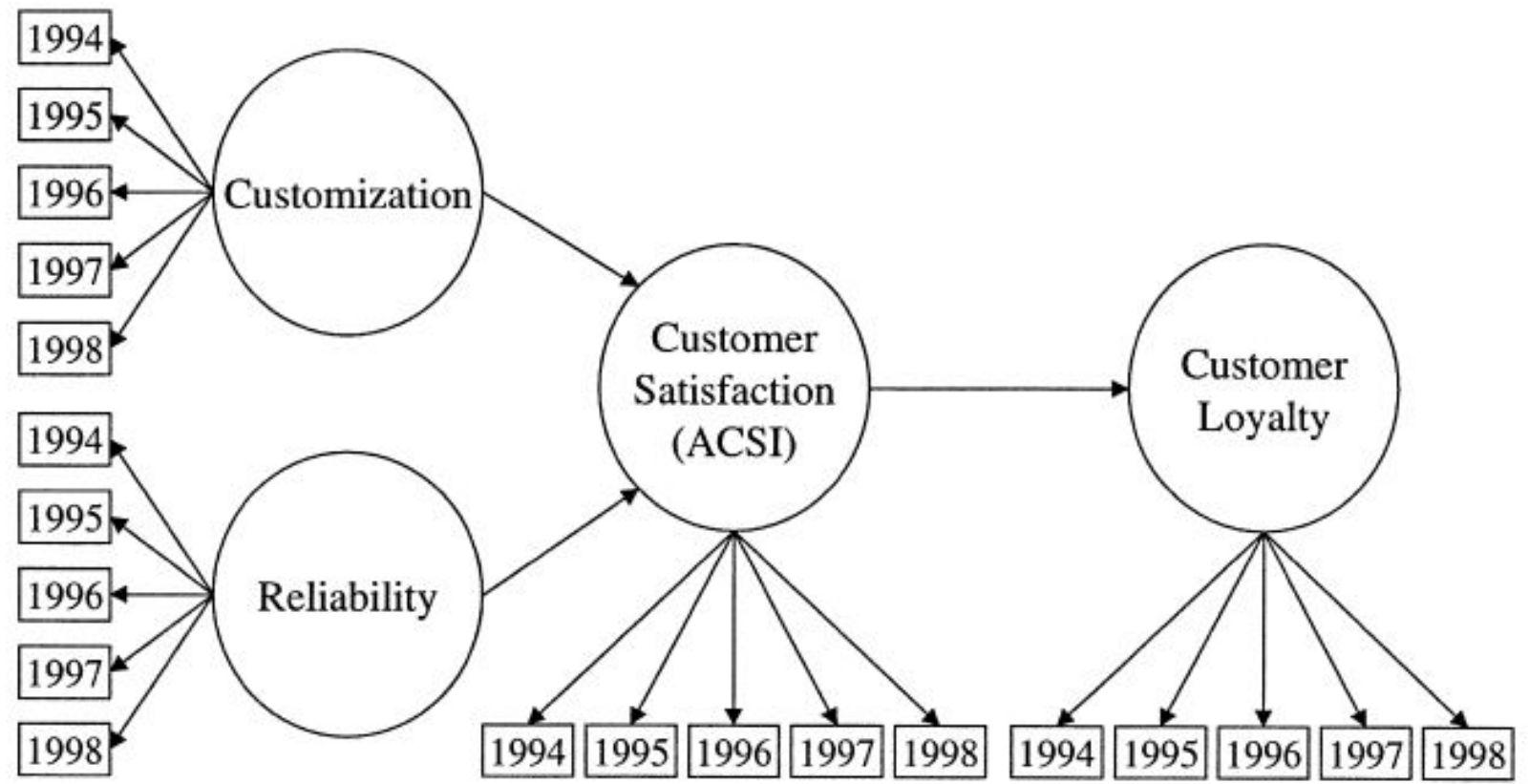

Fig. 1. The research model.

they show the impact that each quality driver has on satisfaction across R\&D categories. Second, the models treat satisfaction as mediating the effects of quality on loyalty, which is consistent with the established causal relationships among these constructs (Gustafsson \& Johnson, 1997).

In order to use all 5 years of available data, we follow Fornell and Johnson's (1993) approach and use the year-to-year observations as reflective measures of an underlying, stable level of each construct. Reliability, customization, satisfaction, and loyalty are measured using observations for the firms from 1994 through 1998. Given the extreme serial (year-to-year) correlation in this type of data, this approach essentially extracts the stable level of each construct as a latent variable for use in estimating the impacts of customization and reliability on satisfaction and subsequent loyalty.

Statistical estimation of a satisfaction model (such as the model in Fig. 1) should accommodate a network of cause-and-effect relationships (from quality, to satisfaction, to loyalty) that contains latent variables. We use partial least squares (PLS) to estimate the model, which is particularly well suited to the skewed data and small samples that are typical in quality and satisfaction data (Gustafsson \& Johnson, 1997; Steenkamp \& van Trijp, 1996). PLS is essentially an iterative estimation procedure that integrates principal-components analysis with multiple regression (Fornell \& Cha, 1994). The objective of PLS is to explain variance in the endogenous variables in the model, in this case satisfaction and loyalty. PLS models were estimated separately for the low, moderate and high technological intensity firms. Jackknife analysis was then used to determine the significance of the parameter estimates.

In addition to the PLS analyses, we estimate a general linear model to determine whether the influence of customization and reliability on satisfaction varies significantly by level of technological intensity. This analysis uses the R\&D categories as a three-level factor, a 5-year weighted average for 
both customization and reliability as covariates and a 5-year weighted average for satisfaction as the dependent variable. The weighted averages were again determined by taking the first principle component for each set of measures across the 5 years of observation.

\section{Results}

The PLS models illustrate the relative impact of each quality dimension on satisfaction. The time series successfully isolated stable levels of customization, reliability, satisfaction, and loyalty for each firm. This is indicated by the average communality of the measurement variables, which is the squared correlation (loading) between each measure and its latent variable. The average communality exceeded the suggested criteria of .5 for every construct in each case (see Fornell \& Cha, 1994), indicating high reliability among the measures. The average communality across constructs was .808, .852, and .796, respectively, for the low, moderate, and high R\&D intensity models. These same models explained 94\%, $96 \%$, and $94 \%$ of the variation in satisfaction and $23 \%, 64 \%$, and $59 \%$ of the variation in loyalty respectively. The latter result suggests that customers are relatively loyalty to particular low R\&D firms and their products - variation in satisfaction has less effect on their loyalty. This is consistent with consumers moving from problem solving to routinized behavior as a product category and its technology become quite mature (Howard, 1983).

The impacts for reliability and customization on satisfaction are illustrated in Fig. 2. For low R\&D firms, customization dominates reliability in its impact on satisfaction (.893 vs. .083). Recall that we predict this on the basis of constantly changing and heterogeneous customer demand as well as firmlevel differences in dematuration (the creative use of old technology) among low-tech products. The Jackknife analysis shows the impact of customization as highly significant $(\mathrm{P}<.001)$ while the impact of reliability as not significant. For moderate R\&D firms, reliability has the significant impact $(.587, \mathrm{P}<.05)$ while the impact of customization is only marginally significant $(.442, \mathrm{P}<.10)$. Importantly, and consistent with Hypothesis 2, the impacts are not significantly different from each other. For high R\&D firms, where we predict that customization is what customers are looking for (technological advancements to better serve their needs), customization once again dominates in terms of impact on satisfaction. The impact of customization $(.855)$ is significant $(\mathrm{P}<.001)$, while the impact of reliability (.138) is not significant.

The sample of firms in this analysis are predominantly manufacturers of durable or nondurable products, with the exception of the four telecommunications firms (GTE, Nynex, Pacific Telesis Group, and AT\&T). There is some concern that these four firms may confound our results because reliability is relatively more important for services firms when compared to manufacturing firms (Johnson \& Nilsson, 2000). To explore this possibility, we removed AT\&T from the moderate R\&D category and removed GTE, Nynex, and Pacific Telesis from the low R\&D category and reran the PLS models for these groups. Removing the firms had no significant effect on the results. The impacts for customization and reliability for low $R \& D$ firms in the smaller sample $(n=25)$ were .873 and .086 , respectively (compared to .893 and 


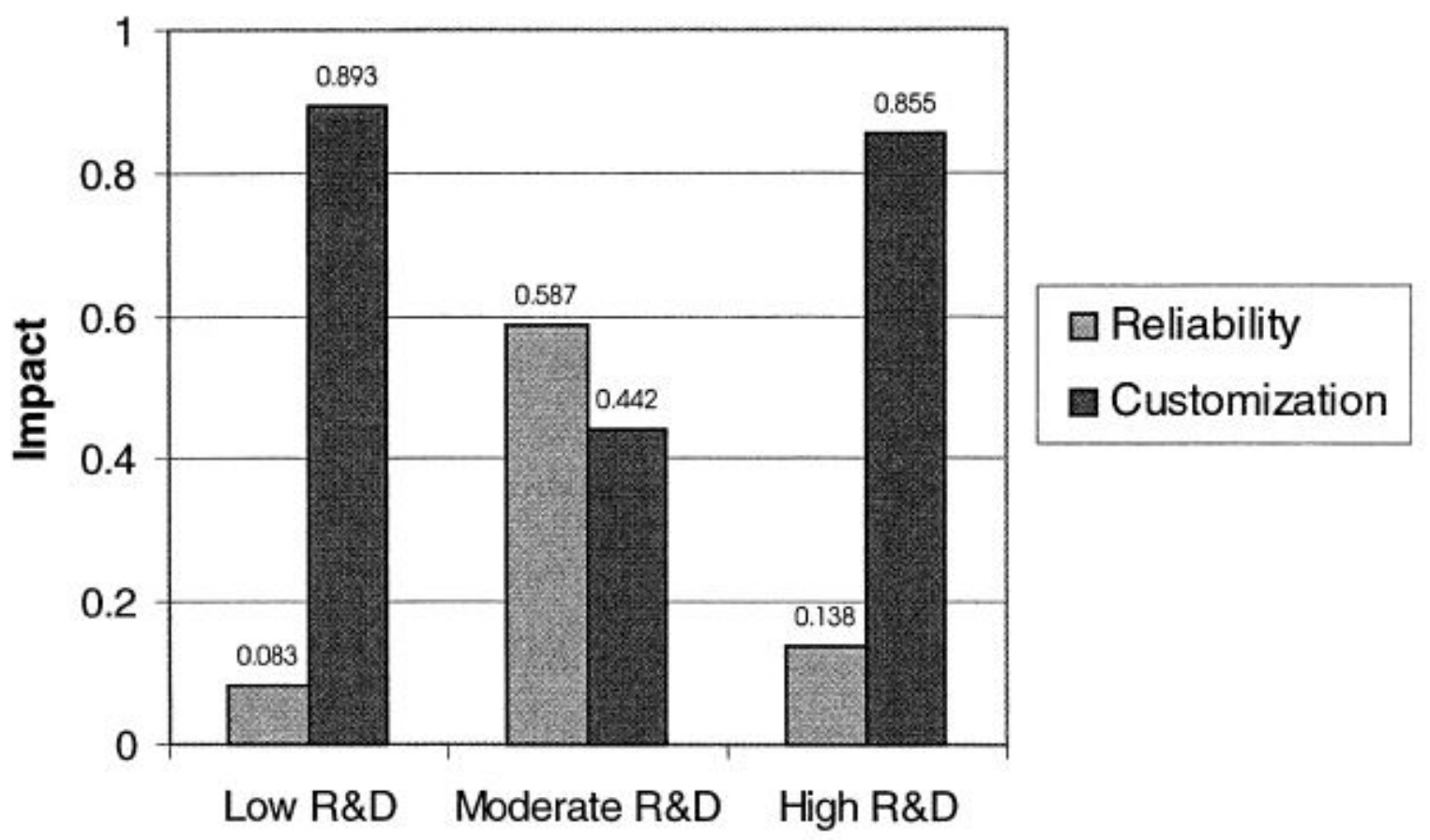

Fig. 2. The impact of reliability versus customization on satisfaction.

.083 in the larger sample). The impacts for customization and reliability for moderate R\&D firms in the smaller sample $(\mathrm{n}=10)$ were .454 and .574 , respectively (compared to .442 and .587 in the larger sample).

The ANOVA results from estimating the general linear model are presented in Table 2. The model explains $96 \%$ of the variation in satisfaction. (A MANOVA analysis using both satisfaction and loyalty as dependent variables in the same analysis yields the same pattern of results reported here.) There is a significant $(\mathrm{P}<.05)$ main effect for both reliability and customization on overall customer satisfaction. The effect of customization is stronger than the effect of reliability, which is consistent with previous ACSI analyses (Fornell et al., 1996) and our PLS results. There is also a marginally significant main effect of R\&D category on satisfaction, where overall satisfaction is slightly higher for low intensity products. These are predominantly consumer nondurable products that receive high satisfaction and loyalty marks from customers in the ACSI survey.

Importantly, the impact of reliability on satisfaction varies as a function of R\&D category as revealed by the significant two-way interaction involving these variables. In contrast, the interaction involving customization and R\&D category does not approach significance. The parameter estimates for these interactions reveal a pattern of results that is consistent with the hypotheses. The impact of reliability on customization is greatest among moderate R\&D firms, lower among high R\&D firms, and lower still among low R\&D firms, which is very consistent with our PLS results. The impact of customization does not vary overall from category to category. The observed significant interaction involving customization and reliability suggests that satisfaction increases even more when a firm excels at both quality drivers. Finally, the results reveal a three-way interaction involving customization, reliability, and R\&D category. That is, the product (interaction) of customization and reliability has a greater impact on satisfaction among moderate and high R\&D firms. 
The key observation is that, as hypothesized, customization and reliability have different impacts on satisfaction depending on the R\&D category, and the pattern of effects is consistent with our theoretical predictions. Overall, the results support hypotheses 1, 2, and 3, and a strong nonmonotonic relationship for the relative impact of reliability versus

Table 2

Satisfaction ANOVA results

\begin{tabular}{lcrlrl}
\hline Source & Sum of squares & df & Mean square & \multicolumn{1}{l}{$F$} & Significance \\
\hline Intercept & 0.190 & 1 & 0.190 & 3.420 & .072 \\
R\&D category & 0.332 & 2 & 0.166 & 2.984 & .062 \\
Reliability & 1.195 & 1 & 1.195 & 21.493 & .000 \\
Customization & 6.024 & 1 & 6.024 & 108.352 & .000 \\
R\&D Category $\times$ Reliability & 0.460 & 2 & 0.230 & 4.140 & .023 \\
R\&D Category $\times$ Customization & 0.019 & 2 & 0.009 & 0.170 & .845 \\
Reliability $\times$ Customization & 0.622 & 1 & 0.622 & 11.181 & .002 \\
R\&D Category $\times$ Reliability $\times$ Customization & 0.589 & 2 & 0.294 & 5.297 & .009 \\
Error & 2.280 & 41 & 0.056 & & \\
Total & 52.000 & 53 & & & \\
\hline
\end{tabular}

$R^{2}=.956$ (adjusted $R^{2}=.944$ ).

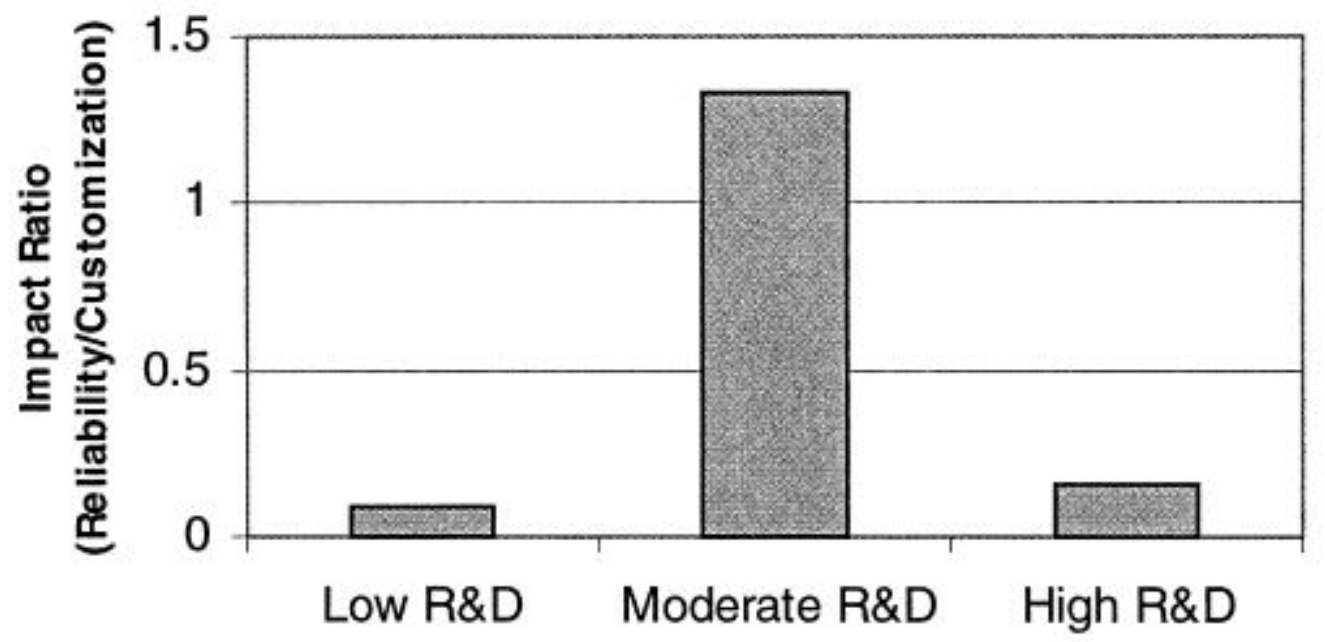

Fig. 3. The ratio of reliability impact to customization impact.

customization on satisfaction across R\&D levels. Fig. 3 uses the PLS impact scores to show that reliability has its greatest relative impact at moderate levels of R\&D spending among our sample of firms. Section 5 of the paper discusses the meaning of these results for both technology and marketing management.

\section{Discussion}

Quality is a key to improving customer satisfaction and loyalty. Yet, quality itself is achieved by improving a product's requirements or specifications (increased customization) and/or reducing things 
gone wrong (increased reliability). Our study integrates dynamic theories of competition and market behavior with an evolutionary theory of technology to develop a model of the relative impact of customization versus reliability on satisfaction and loyalty across levels of technological intensity. The model predicts that customization is relatively more important among high $R \& D$ intensity firms where technological advances have their greatest impact on improving customer requirements. Among more moderate R\&D intensity firms, product innovation and process innovation should have more equal impact as differences in 'things-gone-wrong"' become more important. Among more mature technologies, or low R\&D intensity firms, customization again becomes the important driver of satisfaction as process improvements mature and firms “demature” their technology. That is, they use existing technology in new and creative ways to meet ever changing customer needs.

In our study of 53 manufacturing firms in the ACSI survey, we found that technology (R\&D) intensity significantly moderates the relative impact that customization and reliability have on customer satisfaction and subsequent loyalty evaluations. Whereas customization is the more important driver of satisfaction and loyalty among high and low R\&D intensity firms, reliability and customization are more equally important among moderate R\&D intensity firms. Overall, the results support an inverted-U shaped relationship between the relative impact of reliability versus customization on satisfaction and the technological intensity of the firms in our study.

Our results provide general support for the emergent dynamic theory of competition (Dickson, 1992; Hunt \& Morgan, 1995). An important component of the dynamic view, and our predictions, is that, even though technologies and process improvements mature, customer needs continue to evolve and change over time. As a result, there is significant heterogeneity in customer demand that is not met by existing products even at the mature stage of a technology life cycle. Within Dickson's model, our results suggest that firms shift their resources from innovation, to learning and imitation, to implementation as their technology matures. However, they never achieve complete congruence between supply and demand because of constantly changing consumer demand.

Our results are also consistent with adaptive views of technology management, wherein firms adapt to an aging technology by first moving their resources to process-based improvements and then “dematuring', existing technology by reconfiguring the technology to meet particular market segmentlevel needs. The way in which the resources and strategies of companies are focused is very much dependent upon the maturity of their core technology. Our results provide empirical support for a common view within companies that it is more important to introduce new technologies before all reliability problems are solved.

There are two important implications of these results for strategic management of the technology-quality process. First, companies can more efficiently allocate technology resources for existing product lines by following the normative patterns suggested in these results. Early in the product life cycle, extensive investments in reliability improvements are not warranted. It is only after the dominant design has emerged that reliability improvement has its greatest payoff. Secondly, general managers need to think carefully about the portfolio of products currently offered and how this mix can be reconciled with product plans. Those future investments that require new technology need to be positioned in a way that maximizes the entire portfolio of offerings. Some will require little or no technology or capital investments, while others will require new platforms and significant new product investments. Still others will require working relationships with technology suppliers.

A central rationale underlying these hypotheses is that firms allocate resources to improve quality along two dimensions (customization and reliability). However, this rationale makes two important assumptions regarding internal routines in organizations. First, it assumes that technological resources will actually be expended for quality improvement and are guided or "aligned" by a consistent, cohesive strategy. Second, the rationale discounts the use of other resources (such as empowerment and continuous 
improvement) for quality improvement. Future research should be directed toward understanding how such factors affect both our predictions and results. 


\section{References}

1. Alderson, W. (1957). Marketing behavior and executive action: a functionalist approach to marketing theory. Homewood, IL: Irwin.

2. Alderson, W. (1965). Dynamic marketing behavior. Homewood, IL: Irwin.

3. Barney, J. (1991). Firm resources and sustained competitive advantage. Journal of Management, 17, $99-120$.

4. Best, R. J. (2000). Market-based management: strategies for growing customer value and profitability (2nd ed.). Upper Saddle River, NJ: Prentice Hall.

5. Choi, T. Y., \& Rungtusanatham, M. (1999). Comparison of quality management practices: across the supply chain and industries. Journal of Supply Chain Management, 35, 20 - 27.

6. Cole, R. E. (1998). Learning from the quality movement: what did and didn't happen and why? California Management Review, 41, 43 - 73.

7. Conner, K. R. (1991). A historical comparison of resource-based theory and five schools of thought within industrial organization economics: do we have a new theory of the firm? Journal of Management, 17, 121 - 154.

8. Crosby, P. B. (1980). Quality is free. New York: Penguin Books.

9. Deming, W. E. (1981). Management of statistical techniques for quality and productivity. New York: New York University.

10. Dickson, P. R. (1992). Toward a general theory of competitive rationality. Journal of Marketing, 56, 69-83.

11. Ettlie, J. E. (2000). Managing technological innovation. New York: Wiley.

12. Ettlie, J. E., \& Johnson, M. D. (1994). Product development benchmarking versus customer focus in applications of quality function deployment. Marketing Letters, 5, $107-116$.

13. Feigenbaum, A. V. (1991). Total quality control: fortieth anniversary edition. New York: McGraw-Hill.

14. Fornell, C., \& Cha, J. (1994). Partial least squares. In: R. P. Bagozzi (Ed.), Advanced methods of marketing research (pp. 52 - 78). Cambridge, MA: Blackwell.

15. Fornell, C., \& Johnson, M. D. (1993). Differentiation as a basis for explaining customer satisfaction across industries. Journal of Economic Psychology, 14, 681 - 696.

16. Fornell, C., Johnson, M. D., Anderson, E. W., Cha, J., \& Bryant, B. E. (1996). The American Customer Satisfaction Index: nature, purpose and findings. Journal of Marketing, 60, 7 - 18.

17. Garrison, R. (1978). Austrian macroeconomics. In: L. M. Spadaro (Ed.), New directions in Austrian economics. Kansas City, MO: Sheed, Andrews and McMeel.

18. Garvin, D. A. (1984). What does ‘product quality’ really mean? Sloan Management Review, 26, $25-43$.

19. Griffin, A., \& Hauser, J. R. (1996). Integrating R\&D and marketing: a review and analysis of the literature.

20. Journal of Product Innovation Management, 13, 191 - 215.

21. Gustafsson, A., \& Johnson, M. D. (1997). Bridging the quality-satisfaction gap. Quality Management Journal, 4, 27 - 43.

22. Howard, J. A. (1983). Marketing theory of the firm. Journal of Marketing, 47, 90 - 100.

23. Hunt, S. D., \& Morgan, R. M. (1995). The comparative advantage theory of competition. Journal of Marketing, 59, 1 - 15.

24. Imai, M. (1997). Gemba kaizen: a commonsense, low-cost approach to management. New York: McGraw-Hill. Johannsen, C. G. (1996a). Strategic issues in quality management: 1 . Theoretical considerations. Journal of Information Science, 22, 155 - 164. 
25. Johannsen, C. G. (1996b). Strategic issues in quality management: 2. Survey analysis. Journal of Information Science, 22, 231 - 245.

26. Johnson, M. D. (1998). Customer orientation and market action. Upper Saddle River, NJ: Prentice Hall.

27. Johnson, M. D., \& Nilsson, L. (2000). The impact of reliability and customization on customer satisfaction for goods versus services. Working Paper No. 00-027. Ann Arbor MI: University of Michigan Business School.

28. Juran, J. M., \& Gryna, F. M. (1988). Juran's quality control handbook (4th ed.). New York: McGraw-Hill. Kano, N., Seraku, N., Takahashi, F., \& Tsuji, S. (1984). Attractive quality and must-be quality. Quality, 14, 39-44.

29. Lin, S. A. Y. (1996). Causes of Japanese firms’ direct investments in US manufacturing industries. Applied Economics, 28, 1143 - 1151.

30. March, J. G., \& Simon, H. A. (1958). Organizations. New York: Wiley.

31. Margolis, R. M., \& Kammen, D. M. (1999). Evidence of under-investment in energy R\&D in the United States and the impact of federal policy. Energy Policy, 27, 575 - 584.

32. Morgan, N. A., \& Piercy, N. F. (1998). Interactions between marketing and quality at the SBU level: influences and outcomes. Journal of the Academy of Marketing Science, 26, 190 - 208.

33. Nelson, R. R., \& Winter, S. G. (1982). An evolutionary theory of economic change. Cambridge, MA: Harvard University Press.

34. Parasuraman, A., Zeithaml, V. A., \& Berry, L. L. (1985). A conceptual model of service quality and its implications for future research. Journal of Marketing, 49, $41-50$.

35. Porter, M. E. (1996). What is strategy? Harvard Business Review, 74, 61 - 78.

36. Raynor, M. E. (1992). Quality as a strategic weapon. Journal of Business Strategy, 13, 3-10.

37. Recardo, R. J. (1993). Transitioning to strategic quality management. Journal for Quality and Participation, 16, 48 - 52.

38. Reekie, D., \& Savitt, R. (1988). Marketing behavior and entrepreneurship: a synthesis of Alderson and Austrian economics. European Journal of Marketing, 16, 55 - 66.

39. Reeves, C. A., \& Bednar, D. A. (1994). Defining quality: alternatives and implications. Academy of Management Review, 19, 419 - 445.

40. Steenkamp, J.-B. E. M., \& van Trijp, H. C. M. (1996). Quality guidance: a consumer-based approach to food quality improvement using partial least squares. European Review of Agricultural Economics, 23, 195 - 215.

41. Tushman, M. L., \& Anderson, P. (1986). Technological discontinuities and organizational environments. Administrative Science Quarterly, 31, 439 - 465.

42. Utterback, J. M., \& Abernathy, W. J. (1975). A dynamic model of process and product innovation. Omega, 3, $539-656$.

43. Viscusi, W. K., \& Moore, M. J. (1993). Product liability, research and development, and innovation. Journal of Political Economy, 101, 161 - 185. 